\title{
Hannah Arendt e Walter Benjamin: Eros da amizade e afinidades eletivas em tempos sombrios*
}

Maria Francisca Pinheiro Coelho**

Resumo: Quando se faz referências às relações entre Hannah Arendt (1906-1975) e Walter Benjamin (1892-1940) a menção sempre lembrada é a da amizade. Nas homenagens prestadas à Hannah Arendt por ocasião de sua morte, o filósofo Hans Jonas - amigo de Arendt desde o tempo que foram colegas na universidade em Marburg e alunos de Heidegger - destacou sua vocação para a amizade. Segundo ele, o que a movia era o Eros da amizade (Eros der Freundschaft). No círculo dos amigos mais próximos, incluía-se Walter Benjamin, com quem convivera no exílio em Paris entre os anos 1936 e 1940. E a amizade como pensada e cultivada na prática pelos dois pensadores situava-se no centro de suas vidas, como laço afetivo e visão de mundo. Este paper aborda a relação entre Arendt e Benjamin em dois âmbitos: a amizade, construída na situação de filósofos judeus-alemães refugiados em Paris, e as afinidades eletivas na concepção da história e da modernidade.

Palavras-chave: Hannah Arendt. Walter Benjamin. Exílio. Eros da amizade. Afinidades eletivas.

\section{Hannah Arendt and Walter Benjamin: Eros of friendship and elective affinities in dark times}

Abstract: When we talk about the relationship between Hannah Arendt (1906-1975) and Walter Benjamin (1892-1940) the friendship is always remembered. The philosopher Hans Jonas - Arendt's friend since they were classmates at the University in Marburg and Heidegger's students - in the tributes paid on the occasion of her death, highlighted her vocation for friendship. According to him, what moved her was the Eros of friendship (Eros der Freundschaft). Among her closest friends, there was Walter Benjamin, with whom she was familiar during the exile in Paris, in the years from 1936 to 1940. What I would like to show is that friendship as conceived and grown in practice by the two thinkers would be in the center of their life as a moral trace. This paper aims to broaden the relationship between Arendt and Benjamin in two areas: friendship, built in the situation of Jewish-German refugees philosophers in Paris, and the elective affinities to the concept of history and to the vision of modernity.

Keywords: Hannah Arendt. Walter Benjamin. Exile. Eros of Friendship. Elective affinities.
Recebido: 04.11.19 Aprovado: 31.07 .20

\footnotetext{
* Este artigo é uma versão ampliada do texto "Hannah Arendt and Walter Benjamin: Eros of friendship and elective afinities in dark times", publicado no London Journal of Research in Humanities and Social Sciences, v. 19, Issue 4, Aug. 2019. A autora foi bolsista Capes/professora visitante no exterior sênior, na instituição Freie Universität Berlin, Alemanha, no período de agosto 2018 a julho 2019/Processo 88881.171378/201801 , com pesquisa sobre os dois autores. Em Berlim, os estudos foram concentrados no Walter Benjamin Archiv, da Academie der Künste.

Anos antes, a autora pesquisou nos arquivos Hannah Arendt, em Oldenburg, Alemanha (em janeiro de 2014), e em Nova York, na New School University (em julho de 2014).

** Maria Francisca Pinheiro Coelho é
} 
professora titular do Departamento do Sociologia, Universidade de Brasília (UnB), Brasil. Orcid: 0000-00034357-7267.

<coelhofrancisca@ gmail.com>.
Contar história sempre foi a arte de contar de novo, e ela se perde quando as histórias não são mais conservadas. Ela se perde porque ninguém mais fia ou tece enquanto ouve a história. Quanto mais o ouvinte se esquece de si mesmo, mais profundamente se grava nele o que é ouvido. Quando o ritmo do trabalho se apodera dele, ele escuta as histórias de tal maneira que adquire espontaneamente o dom de narrá-las.

Walter Benjamin, O narrador (1987a).

Os grandes feitos e obras de que são capazes os mortais, e que constituem o tema da narrativa histórica, não fazem parte de uma totalidade ou de um processo abrangente. A ênfase da narrativa histórica recai sempre em situações únicas e rasgos isolados. Essas situações únicas, feitos ou eventos, interrompem o movimento circular da vida diária. O tema da história consiste nessas interrupções - o extraordinário, em outras palavras.

Hannah Arendt, O conceito de história antigo e moderno (1988b).

\section{Introdução}

E ste artigo visa abordar a relação entre Hannah Arendt (1906-1975) e Walter Benjamin (1892-1940) - filósofos, judeus alemães, exilados - durante os anos que conviveram em Paris, entre 1936 e 1940. O argumento defendido é que a interação entre os dois filósofos não se restringia apenas a uma relação de amizade, como amplamente mencionado nas biografias de Arendt (Young-Bruehl, 1982; Adler, Laure, 2007). Existiriam também afinidades no pensamento dos dois autores, que podem ser descritas por meio do conceito de afinidades eletivas. Ao se sugerir abordar a interface entre o pensamento de Arendt e Benjamin por meio do conceito de afinidades eletivas, o objetivo é aproximar o diálogo entre os dois pensadores.

A amizade entre os dois filósofos é tema conhecido na literatura sobre Hannah Arendt. Elisabeth Young-Bruehl (1982), em seu premiado livro Hannah Arendt, for love of the World descreve que no período do exílio, o parceiro intelectual que o 
casal Arendt-Blücher respeitava acima de todos era o crítico literário Walter Benjamin. Em 9 de agosto de 1940, uma das últimas cartas de Benjamin foi para Hannah Arendt. Na carta, escrita em francês, ele se refere aos seus documentos pessoais para sair do país e faz menções carinhosas à mãe de Arendt, Martha Arendt, e a Heinrich Blücher, seu segundo marido, despedindo-se com um "pour vous mes respects les plus gentils. Benjamin"1.

Durante o exílio, em Paris, Benjamin leu o manuscrito do livro de Arendt (1974) Rahel Varnhagen, the life of a jewish woman e em carta o recomendou ao amigo de juventude, em Berlim, Gershom Scholem, que tinha se mudado para Jerusalém:

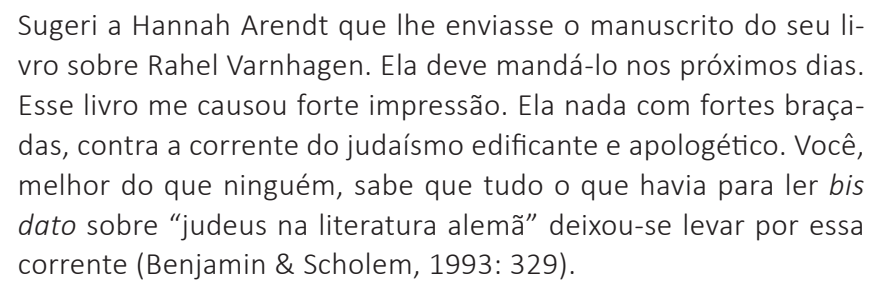

Scholem leu o manuscrito de Arendt e respondeu a Benjamin que o livro muito lhe tinha agradado:

É uma excelente análise do que sucede na época e demonstra que uma ligação baseada em embuste, como era a dos judeus alemães para com a "nação alemã", só podia terminar numa desgraça. [...] Pena que não vejo chance de o livro ser publicado (Benjamin \& Scholem, 1993: 345-346)

Antes de ser apresentada por Benjamin a Gershom Scholem, o amigo já conhecia o trabalho realizado por Hannah Arendt em Jerusalém no transporte de crianças judias da Europa para a Palestina, durante o exílio. Por intermédio de Benjamin, os dois tornaram-se grandes amigos.

Em seus últimos anos em Paris, Benjamin tinha em Hannah Arendt, 14 anos mais jovem, o apoio e a constante companhia. Em setembro de 1940, dias antes de tentar o exílio nos Estados Unidos e a seu pedido, Benjamin se encontrou com Arendt em Marselha, França, e Ihe entregou, entre outros, seu último manuscrito, Teses sobre a filosofia da história, sem título, que em Nova York deveria ser entregue ao Theodor Ludwig Wiesengrund-Adorno (1903-1969), como representante do Instituto de Pesquisa Social, depois da Segunda Guerra conhecido como Escola de Frankfurt, do qual Benjamin era membro. A Escola de Frankfurt é também conhecida como fundadora da Teoria Crítica.
1. Hannah Arendt Papers 7.8. General Correspondence. Benjamin Walter 1938 and undated. A consulta desta correspondência foi realizada no Archiv Hannah Arendt, Carl von Ossietzky Universität, Oldenburg Germany, em janeiro de 2014, e na Biblioteca da New School University, Nova York, em julho de 2014. Os originais dos arquivos de Hannah Arendt estão depositados na Biblioteca de Washington, nos Estados Unidos. Cópias digitalizadas deste arquivo estão na New School University, em Nova York e na Carl von Ossietzky Universität, em Oldenburg, na Alemanha.

2. Este livro de Arendt foi publicado nos Estados Unidos e na Alemanha em 1974, seu último livro publicado em vida. 
Conforme descrição de Young-Bruehl, nunca foi desejo de Arendt entregar os manuscritos a Adorno, mas eram instruções do próprio Benjamin. Arendt apelou a Scholem para fazer a mediação e ele falou das dificuldades encontradas e the sugeriu em carta: "Talvez você pudesse acender uma fogueirinha sob o bom homem?" (Young-Bruehl, 1997: 167).

Hannah Arendt cumpre com o pedido do amigo, mas sem antes providenciar uma cópia dos manuscritos. Relata que Theodor Adorno teria ficado surpreso por ela trazer o manuscrito das teses e também que houve uma recepção calorosa. Ao chegar em casa, comentou com seu marido: "Ele nunca será convidado para nossa casa".

De fato, não houve uma aproximação de Hannah Arendt com Adorno nos Estados Unidos, embora ela tivesse muito a colaborar com as publicações e os escritos de Walter Benjamin, tendo mesmo muitas anotações sobre eles. Arendt queixou-se que em relação aos manuscritos sobre as teses da história, ela teria muitas observações a fazer, pelas conversas com o próprio Benjamin. Ela teria enviado seus comentários por escrito a Gershom Scholem, mas que ele não os considerou quando da edição das teses. Criou-se um clima tenso com o amigo, depois da morte de Walter Benjamin, de quem Arendt foi afastada, sobretudo depois que Adorno e Scholem ficaram responsáveis pela publicação da obra de Benjamin.

Hannah Arendt nunca contou com a simpatia nem com uma boa relação com Adorno. Tinha suas reservas em relação aos frankfurtianos, desde que Günther Anders, seu primeiro marido, teve sua tese negada no concurso para professor na Universidade de Frankfurt. Tempos depois, o mesmo aconteceria com Walter Benjamin, só que ele retirou sua tese antes da seleção, quando soube que ia ser reprovado. Em 1938, Horkheimer confessou, em um encontro com Scholem, em Nova York, ter sido um erro não admitir Benjamin na Universidade de Frankfurt (Benjamin \& Scholem, 1993).

Em 1968, Hannah Arendt (2007) editou em Nova York seu ensaio "Walter Benjamin: 1892-1940", como Introdução ao livro de Walter Benjamin Illuminations, com os manuscritos entregues por Benjamin a ela, em Marselha. No mesmo ano, Arendt publicou também seu livro Men in dark times (Homens em tempos sombrios), que inclui também o seu ensaio sobre Benjamin.

Exemplares do ensaio de Hannah Arendt, publicado em vários idiomas, encontram-se catalogados no Walter Benjamin Archiv, em Berlim. Em 2006, foi publicado na Alemanha o livro Arendt und Benjamin, de Detlev Schöttker e Erdmut Wizisla. Este livro sugere uma nova perspectiva de análise sobre a obra de Walter Benjamin. 
Em tempos sombrios e nas relações de amizade e intelectuais entre Hannah Arendt e Walter Benjamin era como se o vento do pensamento de Benjamin soprasse no próprio pensamento de Arendt e vice-versa, criando uma visão de mundo comum. Embora nem sempre as obras dos dois pensadores conversassem entre si, elas dispunham de um potencial comparativo a ser explorado, aqui definido com base no conceito de afinidades eletivas, principalmente em relação às reflexões sobre a modernidade e a história - provavelmente a marca maior do diálogo presente no pensamento dos dois autores.

\section{O conceito de afinidades eletivas}

O conceito de afinidades eletivas - ou atrações eletivas - aparece pela primeira vez na obra do químico sueco Torbern Olof Bergaman em seu livro De attractionimbus electivis, de 1775. Johann Wolfgang Goethe faz uma transposição desse conceito da química para o campo da intersubjetividade e dos sentimentos humanos, em seu último romance As afinidades eletivas, de 1809. De acordo com Goethe, existe afinidade eletiva quando dois seres "buscam-se um ao outro, atraem-se, ligam-se um ao outro e a seguir ressurgem dessa união numa forma (Gestalt) renovada e imprevista" (Goethe apud Löwy, 1989: 15).

Segundo Michel Löwy,

Com o romance de Goethe o termo ganhou direito de cidadania na cultura alemã, como designação de um tipo particular de vínculo entre as almas. É, portanto, na Alemanha que o conceito conhecerá sua terceira metamorfose: a transmutação, por intermédio desse grande alquimista da ciência social que foi Max Weber, em conceito sociológico. Da acepção antiga irá conservar as conotações de escolha recíproca, atração e combinação (Löwy 1989: 15).

Em Weber, o conceito de afinidades eletivas (Wahlverwandtschaften), como também o de afinidades de sentido (Sinnaffinitäten), aparece em três contextos precisos:

i. para caracterizar uma modalidade específica de relação entre diferentes religiões;

ii. para definir um vínculo entre interesses de classe e visões do mundo (Weltanschauungen); e

iii. para analisar a relação entre doutrinas religiosas e formas do ethos econômico, notadamente utilizado em sua obra A ética protestante $e$ o espírito do capitalismo, de 1905. 
Em uma reflexão filosófico-literária - que inclui a busca da verdade por meio da crítica literária do romance de Goethe -, o conceito de afinidades eletivas também foi usado por Walter Benjamin, em seu ensaio, de 1922, "As afinidades eletivas em Goethe" (2009). O romance de Goethe trata de uma paixão "proibida" entre dois amigos, que os leva à solução da morte em busca da salvação. Em uma análise crítica sobre o amor não como sentimento naturalizado, no sentido de uma atração irresistível, provocada pela beleza de Ottilie, a amada de Eduard no romance de Goethe, Benjamin vai falar do amor em um sentido diferente, o do entendimento, da elaboração discursiva e da disposição de querer ficar junto:

Para os que amam de verdade, a beleza do amado não é o decisivo. [...] Com a paixão é diferente. Qualquer diminuição da beleza, por mais fugaz que seja, faz com que a paixão se desespere. Pois só para o amor o bem mais precioso é a bela mulher; para a paixão, o bem mais precioso é a mais bela mulher (Benjamin, 2009: 98).

Ottilie era bela, mas não tinha uma linguagem, não se expressava com palavras, tinha "o silencio da voz moral", define o crítico Walter Benjamin, que também vai fazer uso do conceito de afinidades eletivas em seus estudos sobre Baudelaire e a modernidade.

Para seu emprego nas ciências sociais e culturais, pode-se definir o conceito de afinidades eletivas como um tipo particular de relação que se estabelece entre ideias, configurações sociais ou culturais, não redutivel à determinação causal direta. Em todas as situações, seja nas inter-relações entre sujeitos e obras, seja na convergência entre fenômenos sociais, o conceito de afinidades eletivas corresponde à existência de uma atração e reciprocidades. Trata-se de uma convergência e de atração recíproca entre determinadas situações e fenômenos, bem como de relações interpessoais.

Mesmo ao se considerar as afinidades eletivas entre o pensamento de Hannah Arendt e Walter Benjamin, há um ponto que distingue seus comentadores: enquanto muitas lutas foram travadas em torno do legado de Benjamin, autor aclamado tanto pelos sionistas como pelos marxistas, essa questão não se colocou em nenhum momento em relação ao espólio intelectual de Arendt, considerada pelos comentadores e por ela mesma, uma pensadora independente. Ela mesma primava por essa condição de independência no pensar. Assim definia: "Eu chamo isso de pensar sem corrimão" (I call it thinking without bannister). Essa autodefinição foi oferecida pela filósofa em um debate intitulado "Hannah Arendt on Hannah Arendt" (1979).

Segundo Arendt, os liberais a consideravam marxista e os marxistas a chamavam de conservadora. Confortável nessa posição dizia "eu não caibo em modelos". Também era mais ou menos assim que ela pensava sobre a obra de Benjamin, apesar 
da disputa em torno de seu legado. Segundo Arendt, Benjamin também não se adequava a classificações. Cultivava amigos de diferentes matizes.

\section{Ironia do destino}

Quis o destino que o Arquivo Walter Benjamin, na Academia de Artes (Akademie der Künste), em Berlim, fosse também o depositário do Arquivo de Theodor W. Adorno. Todo acervo de Benjamin encontra-se neste arquivo, tendo o pesquisador acesso a cópias digitalizadas.

No arquivo, o registro de sua relação com Hannah Arendt encontra-se documentado, sobretudo, em três referências principais:

i. No volume 19 das Obras Escolhidas de Walter Benjamin intitulado "Sobre o conceito de história" ("Über den Begriff der Geschichte") ${ }^{3}$.

ii. No livro Illuminations, de Benjamin, editado por Hannah Arendt, em Nova York, em 1968, no qual estão publicados o ensaio de Arendt sobre o filósofo e as "Teses sobre a filosofia da história" ("Theses on the philosophy of history"), título adotado aqui neste trabalho.

iii. E o livro Arendt e Benjamin (Arendt und Benjamin), de Detlev Schöttker e Erdmut Wizisla (Suhkamp, 2006).

Importa discorrer um pouco sobre essas fontes referidas, explicar um pouco mais essas três referências:

i. O volume das Obras completas de Walter Benjamin denominado "Sobre o conceito de história", título dado por Theodor Adorno, e o mais adotado na literatura, também no Brasil, apresenta diferentes versões do manuscrito das Teses, sendo a primeira o manuscrito entregue por Benjamin a Arendt para ser levado a Nova York. Inclui o copidesque do manuscrito sem título e uma cópia digitalizada. São quatro versões diferentes das teses, uma delas de Dora Benjamin, ex-mulher de Benjamin, e uma do próprio Walter Benjamin, Geschichtsphilosophische Reflexionen (Reflexões histórico-filosóficas). Não é objetivo deste trabalho tratar as diferenças existentes nessas várias versões. Era um hábito de Benjamin escrever diferentes versões de seus textos, entregar a diferentes pessoas, ficar monitorando essas versões, até definir a versão final. A segunda parte deste volume das Obras escolhidas é dedicado a comentários de autores sobre as teses.

3. Walter Benjamin Über den Begriff der Geschichte. Suhrkamp, Band. 19, 2010. 
ii. O ensaio de Hannah Arendt Walter Benjamin (1892-1940) sublinha um perfil de pensador independente, um filósofo e crítico literário que não se adéqua a modelos, classificações nem definições $a$ priori. Arendt argumenta que provavelmente a influência maior nele tenha sido o surrealismo, pois tentava "capturar o retrato da história nas representações mais insignificantes da realidade, por assim dizer em 'suas raspas' (Arendt, 1987: 142)". Benjamin cultivava amigos de diferentes perfis, como Gershom Scholem, Bertold Brecht e Theodor Adorno, mas, de acordo com Arendt, não compartilhava uma identidade intelectual com nenhum em particular:

Todavia, nos raros momentos em que se preocupou em definir o que estava fazendo, Benjamin se considerava um crítico literário e se pode dizer que de algum modo aspirava a uma posição na vida, teria sido a de ser "o único verdadeiro crítico da literatura alemã", como colocou Scholem (Arendt, 1987: 135).

Para Arendt, Benjamin, em tudo que escreveu demonstrava ser um escritor sui generis:

Ele tinha uma amarga percepção de que todas as soluções eram não só objetivamente falsas e inadequadas à realidade como o conduziriam pessoalmente a uma falsa salvação, que se chamava Moscou ou Jerusalém (Arendt, 1987: 163).

A única posição para a qual se podia defini-lo era de

un homme de lettres, de cujas perspectivas únicas nem os sionistas nem os marxistas tinham ou poderiam ter consciência (Arendt, 1987: 156).

Segundo Arendt, Benjamin pensava poeticamente. Seu método era o de um caçador de pérolas, que buscava a transformação marinha shakespeariana dos olhos vivos em pérolas, dos ossos vivos em coral.

Uma citação profundamente cética de Kafka, referida por Benjamin em uma de suas cartas para Gershom Scholem, retrata bem o espírito profundamente cético do filósofo: "Ninguém conhece o caminho ao todo / e cada parte já nos cega" (Benjamin \& Scholem, 1993: 180).

iii. O livro Arendt und Benjamin (2006), de Schöttker e Wizisla, é importante fonte atual de pesquisa sobre a relação entre os dois filósofos e resgata por meio de documentos, da correspondência entre eles, de cartas de Arendt para amigos, os mesmos de Walter Benjamin, de 
textos sobre o Instituto de Pesquisa Social, entre outros. Este resgate da relação entre eles e vários atores é importante para recuperar laços afetivos, o contexto do exílio, perseguições e resistências. São reveladores documentos e comentários de Hannah Arendt sobre Instituto de Pesquisa Social.

Com a seleção de fontes documentais, o livro de Schöttker e Wizisla recupera a relação teórica e afetiva entre Arendt e Benjamin, bem como reabre novas possibilidades de pesquisas sobre as filiações teóricas do filósofo.

Os autores do livro sugerem que com o ensaio de Hannah Arendt de 1968, também publicado no livro, e seus próprios relatos sobre Walter Benjamin e suas vinculações teóricas, os caminhos de pesquisa sobre sua obra estão em aberto. Ressaltam que Arendt foi alijada desse processo por suas relações difíceis com o Instituto de Pesquisa Social por quem nutria uma profunda antipatia. Antes da morte de Benjamin, essas relações também eram difíceis para ele próprio e Scholem, o amigo mais próximo de Benjamin. Benjamin seria um filósofo distante e crítico de filiações rígidas e de enquadramento teórico.

Em Paris, pela convivência quase diária com Benjamin, Arendt também era testemunha de suas dificuldades financeiras e de sua falta de status no Instituto de Pesquisa. Gershom Scholem em seu livro Walter Benjamin: a história de uma amizade (1989) menciona que o que mais Benjamin desejava na época era o seu reconhecimento pelo Instituto de Pesquisa Social.

Hannah Arendt no artigo "Walter Benjamin e o Instituto de Pesquisa Social" ("Walter Benjamin und das Institut für Sozialforschung"), reproduzido no livro de Schöttker e Wizisla, descreve as relações de Benjamin com o instituto. Arendt conta que Benjamin não era membro do instituto e não tinha o mesmo status que Adorno, que chegava a criticar seus textos em nome do instituto. Menciona a carta de Adorno de 10 de novembro de $1938^{4}$ para Benjamin, na qual afirma que a obra Baudelaire foi rejeitada, em nome de "nós todos".

4. Briefe [1966], Bd.II, S.p. $782 \mathrm{ff}$.

Arendt descreve que Benjamin nunca decidiu nada e nunca pôde ou quis falar em nome do instituto. Ele foi apontado como "membro da equipe do instituto de Nova York" com um "salário normal" apenas após a eclosão da Segunda Guerra, em 1939. Antes, Benjamin era um colaborador do instituto, recebia por seus escritos, alguns com várias e repetidas recomendações de alteração do texto. 
5. "Man darf hinzufügen, dass trotz aller Konflikte ese ben doch das Institut war, das allein ihm das Leben ermöglichte, und das mit Ausbruch des krieges das Institut wirklich alles nur Menschebnögliche unternommen hat, um ihn zu retten". Schöttker e Wizisla reeditam este texto Walter Benjamin e o Instituto de Ciências Sociais, bem como o ensaio de Hannah Arendt Walter Benjamin (18921940) da Revista Merkur, 22 (1968).

6. "Hannah Arendt, die im Pariser Exil eine Vertraute Walter Benjamin wuesw, hat die Rezeption seiner Schriften wie wenige andere geprägt. 1968 veröffentlichte sie in der Zeitschirift Merkur einen Aufsatz, in dem sie biographische, literarische und politische Aspekte des Werkes in den Mittelpunkt stellte. Zuvor Hatten Gershom Scholem und Theodor Adorno, Banjamin langjähirige Freunde, die philosophische und die theologische Perspektive betont. Arendt warf beiden ein Verdrängung der materialistischen Positionen Benjamins vor [...]. Arendt wollte nicht nur eine vernachluassigte Dimension in Benjamins denken darstellen, sondern sich auch für Verletzungen revanchieren, die ihrem
Hannah Arendt menciona neste texto que especialmente após o conflito sobre Baudelaire, Benjamin se sentiu financeiramente ameaçado e que teria confessado que as próprias circunstâncias que tanto ameaçavam a sua situação europeia tornariam impossível sua transferência para os Estados Unidos. Desde o início estava claro que a bolsa de estudos do instituto que Benjamin recebia dependia inteiramente da recepção do seu trabalho: "Uma recepção boa de seus trabalhos the renovava esperanças".

Entretanto, ao final deste texto sobre as relações de Benjamin com o Instituto de Pesquisa Social, Arendt reconhece:

Pode-se acrescentar que, apesar de todos os conflitos, foi o instituto que por si tornou a vida de Benjamin possível e que, com a eclosão da guerra, o instituto realmente fez tudo o que era humanamente possível para ele se salvar (Schöttker \& Wizisla, 2006: 194, tradução nossa) $)^{5}$.

Erdmut Wizisla e Detlev Schöttker escrevem no Prefácio do livro:

Hannah Arendt, de quem no exílio ganhou a confiança de Walter Benjamin, moldou a recepção de seus escritos como poucos outros. Em 1968, ela publicou um ensaio na revista Merkur em que se concentrou em aspectos biográficos, literários e políticos de seu trabalho. Antes, Gershom Scholem e Theodor W. Adorno, amigos de longa data de Benjamin, haviam enfatizado as perspectivas filosóficas e teológicas. Arendt acusou ambos de reprimirem as posições materialistas de Walter Benjamin. Essa acusação tornou-se parte da controvérsia em torno da edição e interpretação dos escritos de Benjamin, que continua a ocupar a pesquisa até hoje [...]. Arendt não só quis retratar uma dimensão negligenciada no pensamento de Benjamin, como também queria retratar os ferimentos infligidos a ela. Era uma reminiscência das dependências financeiras e medidas intelectuais que Benjamin teve que tomar no exílio (Schöttker \& Wizisla, 2006: 9, tradução nossa) ${ }^{6}$.

\section{Amizade e afinidades eletivas em tempos sombrios}

Em setembro de 1940, dias antes de tentar o exílio nos Estados Unidos e a seu pedido, Walter Benjamin encontrou-se com Arendt em Marselha, França. Ele entregou a Arendt, entre outros manuscritos, seu último escrito que versava sobre as teses sobre a filosofia da história, que, em Nova York, deveria ser entregue a Theodor W. Adorno, como representante do Instituto de Pesquisa Social. 
O contato frequente e a amizade entre Arendt e Benjamin constituíam uma segurança emocional naqueles anos de preconceito e perseguição aos judeus na Europa. Laure Adler descreve em seu livro Nos passos de Hannah Arendt (2007) que todo fim de tarde Arendt ia buscar Benjamin na Biblioteca Nacional, em Paris. À noite, eles liam em voz alta e dissecavam textos de Kafka:

\begin{abstract}
Ele encarna para ela o escritor que sabe aflorar o nada e tornar definitivamente absurda qualquer ideia de redenção. Ela é a saída a todos os seus tormentos, a encarnação de sua resistência à teologia, sua fonte de esperança. A cada dia, ele Ihe dá a coragem de viver. A cada noite, ela o ajuda a ultrapassar seu desespero (Adler, 2007: 148).
\end{abstract}

No percurso para a análise das afinidades intelectuais no pensamento de Hannah Arendt e Walter Benjamin, o ponto de partida sugerido neste artigo é a relação de amizade entre eles. A partir dessa inter-relação vão-se tecendo as afinidades eletivas. Amizade e afinidades eletivas são partes indissociáveis da relação entre os dois filósofos. A companhia de um ao outro Ihes renovava esperanças.

O Eros da amizade no sentido do cultivo das relações afetivas de Hannah Arendt com os amigos estaria próximo da compreensão de Aristóteles (1992) em Ética a Nicômacos, da amizade como excelência moral; a amizade relacionada à convivência humana e, por consequência, com a própria coisa pública. Embora Arendt se referisse ao seu mundo particular ao falar dos amigos, esse mundo também tinha a dimensão do mundo no qual ela se sentia segura em relação ao mundo lá fora, em que a maior parte do tempo se sentia uma estranha.

Contudo, pode-se dizer, que os laços de amizade de Arendt com os amigos também continham a compreensão da amizade como definida por Cícero (2006), a amizade mais concentrada nos laços pessoais e afetivos. Nesse sentido, sugere-se que o significado do cultivo da amizade em Arendt envolve tanto a compreensão da amizade como excelência moral de uma relação com o mundo, em Aristóteles, quanto a amizade como laço afetivo entre pessoas que se admiram. Walter Benjamin era seu amigo, mas com ele também compartilhava uma visão do mundo lá fora.

Para Arendt e Benjamin, o mundo particular dos amigos tinha uma profunda ligação com o mundo público, mundo no qual a maior parte do tempo se sentiam fora de casa. O contato frequente e a amizade entre os dois filósofos constituíam uma segurança emocional naqueles tempos de preconceito e perseguição. Em tempos sombrios, expressão de Bertold Brecht, que Hannah Arendt utiliza para nomear seu livro Homens em tempos sombrios (1987), ela precisava se reconciliar o tempo 
7. Reproduzido de Elisabeth YoungBruehl, Por amor ao mundo: a vida e a obra de Hannah Arendt, 1997: 164 e 422 . todo com o mundo. O sentimento de pertencimento ao mundo se realizava por intermédio do mundo particular dos amigos. Arendt menciona que os tempos sombrios não são novos, como não constituem uma raridade na história. Entretanto, argumenta que mesmo no tempo mais sombrio temos o direito de esperar alguma iluminação e que tal iluminação pode bem provir menos de teorias e conceitos, mas da história de homens e de grandes obras.

Em 1941, na viagem para o exílio para os Estados Unidos, Arendt e seu marido Heinrich Blücher leem no navio em voz alta para os passageiros o manuscrito levado por ela das Teses sobre o conceito de história (Adler, 2007). Em 1942, em Nova York, Hannah Arendt escreveu um poema para Walter Benjamin:

W. B.

O crepúsculo voltará algum dia.

A noite descerá das estrelas, Repousaremos nossos braços estendidos

Nas proximidades, nas distâncias.

Da escuridão soam suavemente

Pequenas melodias arcaicas. Ouvindo,

Vamos desapegar-nos,

Vamos finalmente romper as fileiras.

Vozes distantes, mais perto de luto.

Essas são as vozes e esses os mortos

Pré-enviados como mensageiros

$\mathrm{Na}$ frente, para levar-nos no sono ${ }^{7}$.

\section{Sobre o conceito de história}

\section{e a visão de modernidade}

As referências principais aqui utilizadas são os textos de Hannah Arendt "O conceito de história: antigo e moderno" e "A tradição e a época moderna", ambos reunidos em sua obra Entre o passado e o futuro (1988). E de Walter Benjamin seu último escrito - Teses sobre a filosofia da história.

A cópia de Walter Benjamin das Teses sobre a filosofia da história publicadas no volume 19 de suas Obras escolhidas (2010) tem como título Reflexões histórico-filosóficas (Geschichtsphilosophische Reflexiones). Pode-se observar que o título dado por Hannah Arendt às teses é próximo do título do manuscrito póstumo de Walter Benjamin.

Embora nem sempre as obras dos dois pensadores conversem entre si, elas dispõem de um potencial comparativo a ser explorado. Nesse sentido, julga-se aqui 
que em uma proposta mais ampla de pesquisa sobre o pensamento dos dois filósofos, as questões e as reflexões sobre a concepção da história e a visão crítica da modernidade sejam provavelmente a marca maior do diálogo presente entre eles.

Há uma semelhança também entre Arendt e Benjamin na maneira literária de pensar. O pensar poeticamente que Arendt atribui a Benjamin poderia também ser estendido a ela, que tem um gosto particular pela literatura e pela arte de contar histórias.

Em Walter Benjamin e em Hannah Arendt há uma crítica ao conceito de história como algo linear, contínuo e universal. Se em Benjamin existe uma crítica ao conceito de história baseado em uma ideia de progresso, uma crítica ao conceito de história que busca certezas absolutas, uma crítica ao conceito de história que busca uma ideia de causalidade (ao desconhecer eventos e acontecimentos ocasionais, capazes de iluminar um tempo), há nessa compreensão uma identidade com o conceito de história em Hannah Arendt.

Se para Benjamin, o tempo da história é o tempo de "agoras", o tema da história em Arendt é o do extraordinário. Tanto em Benjamin como em Hannah também o particular informa a compreensão do geral. Ao se referir à história antiga que preza pela narrativa dos fatos, Arendt enfatiza:

\footnotetext{
Causalidade e contexto eram vistos sob uma luz fornecida pelo próprio evento, iluminando um segmento específico dos problemas humanos; não eram considerados como possuidores de uma existência independente de que o evento seria apenas a expressão mais ou menos acidental, conquanto adequada (Arendt, 1988: 96).
}

Ao se comparar as Teses sobre a filosofia da história de Walter Benjamin com a concepção da história em Hannah Arendt com base no fato extraordinário, percebe-se que os dois autores de fato estão se remetendo a uma crítica da concepção moderna da história e da própria modernidade como um continuum. Em relação à compreensão da história, as afinidades eletivas entre os dois filósofos concentram-se na crítica da modernidade, devido a uma visão totalizante, e no entendimento de ambos sobre o conceito de história, com foco na capacidade de iluminação de eventos particulares. Para os dois filósofos, a noção de experiência e do significado de eventos particulares são essenciais para a compreensão da história. Segundo Arendt, Walter Benjamin,

[...] em sua preocupação com fatos concretos direta e efetivamente demonstráveis, com eventos e acontecimentos únicos cujo 


\begin{abstract}
"significado" é evidente, Benjamin não estava muito interessado em teorias ou "ideias" que não assumissem imediatamente a mais precisa forma exterior imaginável. Para ele, a relação marxista entre superestrutura e infraestrutura converteu-se, em um sentido preciso, em uma relação metafórica (1987: 143).
\end{abstract}

Em Walter Benjamin, as metáforas são os meios pelos quais se realizam poeticamente a unicidade do mundo. Arendt sublinha que Benjamin, por conseguinte, estava fadado a considerar a metáfora como o maior dom da linguagem, pois para ele, "a 'transferência' linguística nos permite dar forma material ao invisível" (Arendt, 1987: 144).

Os dois filósofos em suas concepções da história reforçam a necessidade de compreensão do significado de experiências particulares, das narrativas históricas, dos eventos extraordinários. Há neles uma nítida preocupação com o tempo presente e o significado de eventos particulares. Ao se referir à modernidade, Arendt menciona uma quebra do fio da tradição, na medida em que o passado já não se comunica com o presente. Nas palavras de Benjamin, o anjo da história ao olhar para trás só vê um amontoado de ruínas.

Walter Benjamin crítica a compreensão da história como uma ciência positivista, posição que expressa em várias passagens de suas teses:

O cronista que narra os acontecimentos, sem distinguir entre os grandes e os pequenos, não leva em conta a verdade de que nada do que um dia aconteceu pode ser considerado perdido na história. Sem dúvida, somente a humanidade redimida poderá apropriar-se totalmente de seu passado. Isso quer dizer: somente para a humanidade redimida o passado é citável em cada um de seus momentos (Tese 3, 1987: 223).

A verdadeira imagem do passado perpassa veloz. O passado só se deixa fixar, como imagem que relampeja irreversivelmente, no momento em que é reconhecido (Tese 5, 1987: 224).

Articular historicamente o passado não significa conhecê-lo "como ele foi". Significa apropriar-se de uma reminiscência, tal como ela relampeja no momento de um perigo (Tese 6, 1987: 224).

Assim como a cultura não é isenta de barbárie, não o é, tampouco, o processo de transmissão da cultura. Para Benjamin, a tarefa do historiador é "escovar a história a contrapelo" (Tese 7, 1987: 225):

A ideia de um progresso da humanidade na história é inseparável da ideia de sua marcha no interior de um tempo vazio e homo- 
gêneo. A crítica da ideia do progresso tem como pressuposto a crítica da ideia dessa marcha (Tese 13, 1987: 229).

A história é objeto de uma construção cujo lugar não é o tempo homogêneo e vazio, mas um tempo de "agoras" (Tese 14, 1987: 229).

No mesmo sentido, para Hannah Arendt o tema da história é a compreensão de eventos particulares capazes de iluminar um tempo. O tema da história é "o extraordinário". Os grandes feitos e as grandes obras de que são capazes os mortais, e que constituem o tema da narrativa histórica, não fazem parte de uma totalidade ou de um processo abrangente: a ênfase recai sempre em situações únicas e rasgos isolados (Arendt, 1988b: 72).

Segundo Arendt, a história como narrativa dos fatos deve considerar elementos, tais como a explanação de fatos e eventos, os relato dos feitos dos vencedores e dos vencidos, a figura dos testemunhos. Inexistiria um conceito de história universal e da humanidade como um todo. Cada evento, feito ou ocorrência é concebido em si e por si mesmo, na medida em que o particular informa a compreensão do geral.

De acordo com Arendt, a ausência de sentido do mundo moderno está prenunciada na identificação entre meios e fins. A quebra do fio da tradição estaria na glorificação da atividade da ação (entendida como fabricação) em relação às atividades da política (entendida como a construção de acordos) e da filosofia (entendida como a atividade do pensamento). A alienação do mundo moderno se caracterizaria pela perda de um mundo comum somente possível no espaço público e na política:

\footnotetext{
A época moderna, sua crescente alienação do mundo, conduziu a uma situação em que o homem onde quer que vá, encontra apenas a si mesmo (Arendt, 1988a: 96).
}

Em síntese, em Walter Benjamin e em Hannah Arendt, a crítica ao conceito moderno de história recai sobre os seguintes elementos: a ideia de progresso, a relação entre causa e efeito, a preocupação com uma explicação generalizada dos fatos, em detrimento do olhar sobre o particular, a influência da visão hegeliana da história como o desenvolvimento ininterrupto do espírito.

\section{Considerações finais}

Sugeriu-se neste exercício comparativo entre o pensamento de Hannah Arendt e Walter Benjamin, construído nos tempos sombrios da Segunda Guerra e tecido a partir de laços profundos de amizade, que as afinidades eletivas entre Hannah 
8. Como postscriptum, acrescentamos uma entrevista da autora com o professor Erdmut Wizisla, um dos autores do livro Arendt und Benjamin (2006), ralizada em Berlim em 25 de julho de 2019. O professor Wizisla é pesquisador do Walter Benjamin Archiv, em Berlim, e especialista das obras de Walter Benjamin e Bertold Brech.

A autora considera importante a publicação desta entrevista porque o professor Erdmut Wizisla, além de tecer comentários sobre o seu livro, Arendt und Benjamin (2006), faz também uma avaliação sobre as ideias e o tema de nossa pesquisa - "Hannah Arendt e Walter Benjamin: Eros da amizade e afinidades eletivas". Atualmente, a pesquisadora dá continuidade aos seus estudos sobre o tema, com bolsa de produtividade do Conselho de Desenvolvimento Científico e Tecnológico - CNPq.
Arendt e Walter Benjamin manifestam-se em particular em relação aos seguintes aspectos: na crítica ao conceito de história que exclui o foco na capacidade de iluminação de eventos particulares; na crítica à noção de modernidade como portadora da ideia de progresso; na noção de experiência individual como algo intransferível; e na valorização da experiência coletiva como capaz de romper com o continuum e criar situações revolucionárias.

No entanto, as semelhanças em relação aos aspectos aqui abordados não apagam o estatuto teórico e a trajetória de cada obra em particular. Em Hannah Arendt, a crítica à modernidade recai em um questionamento profundo da teoria marxista e, em particular, ao próprio Marx, pela glorificação da atividade do trabalho em detrimento da atividade da política, uma característica da ação por excelência e seu potencial de liberdade. Já em Walter Benjamin, a crítica à modernidade recai em uma valorização do materialismo histórico como possibilidade de redenção.

Para os dois filósofos, por meio de eventos particulares ou extraordinários pode-se revelar o espírito de uma época, sem pretensões generalizantes. Refazer histórias e trajetórias singulares contribuem para o conhecimento das ideias que iluminam à compreensão de um tempo e de suas personagens. A crítica ao conceito moderno de história em Hannah Arendt e de um tempo linear e vazio em Walter Benjamin não apenas apresentam conteúdos semelhantes como demonstram ainda afinidades de visões em relação às características e inseguranças da modernidade.

\section{Postscriptum.}

\section{Entrevista com o Dr. Erdmut Wizisla ${ }^{8}$}

Maria Francisca: What were the motivations for writing the book Arendt und Benjamin?

Dr. Erdmut Wizisla: Schöttker and I realized that the relationship between Hannah Arendt and Walter Benjamin hasn't been researched enough. We knew about Hannah Arendt's copy of "Über den Begriff der Geschichte" from the Library of Congress, one of Benjamin's most important texts. It was possible to publish this fascinating manuscript for the first time in this volume. Everyone loved the papers with the different colors.

We thought it would be important to publish Arendt's Benjamin essay from 1968 again. And we found a lot of new documents, at first letters, and I think this volume could contribute to a new image of this relationship. 
Maria Francisca: The book contains a number of important documents, such as the correspondence between Hannah Arendt and Walter Benjamin, letters from Arendt to various close friends and Walter Benjamin's friends, such as Gershom Scholem, Günther Anders, Bertolt Brecht and Theodor W. Adorno.

By including in this book letters and documents what the authors intended to contribute to the knowledge of the relationship between Hannah Arendt and Walter Benjamin?

Dr. Erdmut Wizisla: We wanted to enrich the knowledge about Hannah Arendt and Walter Benjamin. And we had the impression that Benjamin's friends Theodor W. Adorno and Gershom Scholem had an one-sided and affective view on Arendt and on Arendt's relation to Benjamin. To collect all the letters seems us to bring more knowledge and clearness in this matter.

Actually the unknown postcard with this funny and tender reminder of chess matches (and Benjamins remark, his horses would long to bite her horses), was found by a friend of mine, Barbara Hahn, who is an Arendt expert, found an unknown postcard.

Maria Francisca: As a reader of the book, that I think has great relevance for researches on Walter Benjamin and his theoretical affiliations, I would like the professor explain a little more about the essential thesis argued below:

Hannah Arendt, from whom in exile gained the trust of Walter Benjamin, shaped the reception of her writings like few others. In 1968, she published an essay in Merkur magazine in which she focused on biographical, literary, and political aspects of his work. Previously, Gershom Scholem and Theodor W. Adorno, longtime friends of Benjamin, had emphasized philosophical and theological perspectives. Arendt accused both of them of repressing the materialistic positions of Walter Benjamin. This accusation became part of the controversy surrounding the editing and interpretation of Benjamin's writings, which continues to occupy the research to this day.

So far everything seemed clear. However, if you look more closely, the facts become more complex. Arendt not only wanted to portray a neglected dimension in Benjamin's thought, but also want- 
ed to portray the wounds inflicted on her. It was reminiscent of the financial dependencies and intellectual measures that Benjamin had to take in exile. At the same time, she tried to explain Benjamin and Heidegger, whom she also felt compelled to believe, and what can be said to be spiritual thinkers. The test led to irritations at various levels, which were only partially visible in public reactions.

Dr. Erdmut Wizisla: You are right in generally I would say. And your view is absolutely interesting and free of prejudice. That is important.

Hannah Arendt's view on Benjamin has its own tendency and is not free of simplifications. Namely the idea that Benjamin was awkward and clumsy seems to us not really useful. I enclose a paper of mine (from a congress in Portbou in 2010), in which I argued against this perspective. I estimate Hannah Arendt very highly. But I also see that she although she was very close to Benjamin gave him her shape.

I think the interpretation of Benjamin's writing is now in a sort of its classical phase. It is now possible to avoid these old battles and to learn more about how it was, really. It doesn't mean that we should have a non-political view on Benjamin. But we have to read and to understand him in his time.

Maria Francisca: The ideas from the book Arendt und Benjamin led me to think how the reification of a work, in the case of Walter Benjamin due the approaches of Gershom Scholem and Theodor W. Adorno, can lead the reader of Benjamin's work to have wrong view at his work. And, in this case, his premature death may have contributed to such different views.

Does my remark make any sense to you, Professor Wizisla? Is it as if the work no longer belonged to its author?

Dr. Erdmut Wizisla: Benjamin's work is a sort of myth. His many friends contributed to this legend. Some of them altruistic, some with strong interests. I do not want to judge. And I do not want to value who of them was better, who was right, who wrong. The efforts of Adorno and Scholem is amazing, but Hannah Arendt and also Bertolt Brecht took part in their own manner.

Maria Francisca: Would Professor Wizisla have suggestions to give me from other sources of research on Hannah Arendt and Walter Benjamin? 
Dr. Erdmut Wizisla: I am sure you know already all what is important. Look at the correspondence between Hannah Arendt and Gershom Scholem and Hannah Arendt and Günther Anders which hasn't been published when we did this book. Maybe you can also check Heinrich Blücher's papers. Blücher is very important for Benjamin's political position, and he was a close friend as well.

Thank you very much.

Thank you, Maria Francisca. And all the best for your work.

\section{Referências}

ADLER, Laure. Nos passos de Hannah Arendt. Rio de Janeiro: Record, 2007.

ADORNO, Theodor W. Correspondência 1928-1940. In: Adorno-Benjamin. São Paulo: Editora Unesp, 2012.

ARENDT, Hannah. Crises da República. São Paulo: Perspectiva, 1999.

A tradição e a época moderna. In: Entre o passado e o futuro. 2 ed.

São Paulo: Perspectiva, 1988a.

. O Conceito de história - antigo e moderno. In: Entre o passado e o

futuro. 2. ed. São Paulo: Perspectiva, 1988b.

Walter Benjamin: 1892-1940. In: . Homens em tempos sombrios. São

Paulo: Companhia das Letras, 1987.

. Men in dark times. New York: Harcourt Brace \& Company, 1983.

. Hannah Arendt on Hannah Arendt. In: HILL, Melvyn A. (Edited). Hannah

Arendt: the recovery of the public world. New York: St. Martins's Press, 1979.

Rahel Varnhagen, the life of a jewish woman. New York: Harcourt Brace Jovanovich, 1974.

ARISTÓTELES. Ética a Nicômacos. Brasília: Editora Universidade de Brasília, 1992.

BENJAMIN, Walter. Über den Begriff der Geschichte. Suhrkamp verlag Berlin, Band 19, 2010.

As afinidades eletivas em Goethe. In: . Ensaios reunidos: escritos sobre Goethe. São Paulo: Duas cidades; Editora 34, 2009. 
. Illuminations. Edited by Hannah Arendt. New York. Harcourt Brace Jowanovich, Inc. 2007.

- Briefe. Herausgegeben und mit Anmerkungen Verseihen von Gershom Scholem und Theodor W. Adorno. Erster Band. Suhrkamp. Band1 und Band2, 1993. . O narrador. Considerações sobre a obra de Nikolai Leskov. In: Obras escolhidas. v. 1. 3. ed. São Paulo: Brasiliense, 1987a. Sobre o conceito de história. In: . Obras escolhidas. v. 1. 3. ed. São Paulo: Brasiliense, 1987b.

BENJAMIN, Walter; SCHOLEM, Gershom. Correspondência. São Paulo: Perspectiva, 1993.

CíCERO, Marco Túlio. Sobre a amizade. São Paulo: Editora Nova Alexandria, 2006.

GOETHE, Johann Wolfgang von. As afinidades eletivas. São Paulo: Penguin Classics; Companhia das Letras, 2014.

LÖWY, Michel. Redenção e utopia: o judaísmo libertário na Europa Central: um estudo de afinidade eletiva. São Paulo: Companhia das Letras, 1989.

SCHOLEM, Gershom. Walter Benjamin: A história de uma amizade. São Paulo: Perspectiva, 1989.

SCHÖTTKER, Detlev; WIZISLA, Erdmut. Arendt und Benjamin. Deutschland: Suhrkamp, 2006.

YOUNG-BRUEHL, Elisabeth. Hannah Arend, for love of the world. New Haven; London: Yale University Press, 1982.

YOUNG-BRUEHL, Elisabeth. Por amor ao mundo: a vida e a obra de Hannah Arendt. Rio de Janeiro: Relume Dumará, 1997. 